Proc. Estonian Acad. Sci. Eng., 2002, 8, 2, 84-100

\title{
Investigation and design of shallow wooden and composite shell-cable roofs
}

\author{
Karl Õiger \\ Department of Structural Design, Tallinn Technical University, Ehitajate tee 5, 19086 Tallinn, \\ Estonia; koiger@edu.ttu.ee \\ Received 18 March 2002, in revised form 1 April 2002

\begin{abstract}
The paper gives a review of the investigations on the behaviour of shell roofs, carried out at the Tallinn Technical University. The roof structures examined consisted of a board shell or of a prestressed cable network and timber or steel cladding. Edge beams were made from blanks, glulam, or steel tube. Main attention is paid to the influence of the roof cladding (panels) on the behaviour of square and elliptical saddle-shaped suspension roofs.
\end{abstract}

Key words: suspension roof, shell-cable roof, hypar.

\section{INTRODUCTION}

For over 40 years the behaviour of different saddle-shape suspended crossing cable systems has been investigated at Tallinn Technical University. The aim of these investigations has been to study the influence of the geometry, boundary conditions, rigidity of elements, and various methods of strengthening on the work of the shell-cable structures and to find advantages and unfavourable qualities of them. Experimental investigations were conducted on models. To determine the stress-strain state, various analytical and numerical methods were employed. This article discusses the systems shown in Figs. 1 to 3.

The timber shells consisted of two or three board layers, placed parallel to the shell diagonals. Some shells were strengthened by glass-reinforced plastic network or by ribs, placed parallel to the contour beam, or by prestressed steel cables (Fig. 3). Nail and glue-nail fastenings were used. The surface of $H$-type timber shells corresponds to hypar $\left(\beta=f / f_{0}=2\right)$ or to another surface with $\beta=3$.

We have also examined the behaviour of roof shells composed of a suspended prestressed cable network and layered timber shell of elliptical contour, with interconnected components acting as a unit (Fig. 2). 

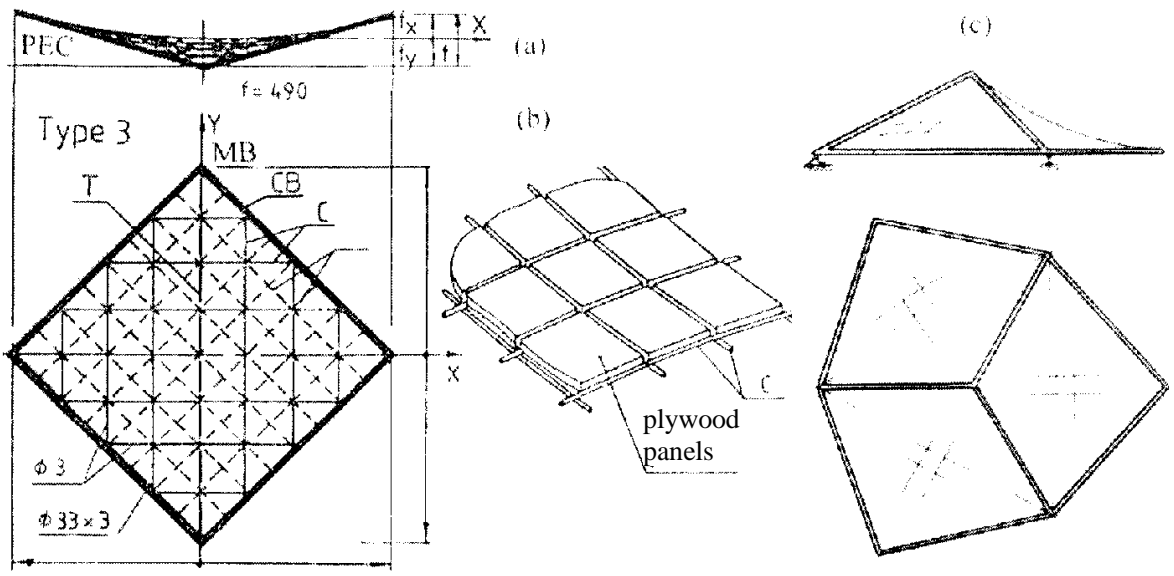

FB

Fig. 1. (a) Scheme of a shell-cable roof: $T$ - tie-rod, $C$ - cables, CB - contour beam, PEC - pinended column, FB - fixed bearing, $\mathrm{MB}$ - freely in the direction of $\mathrm{Y}$ movable bearing; (b) plywood or steel panels; (c) schemes of complex roof models.

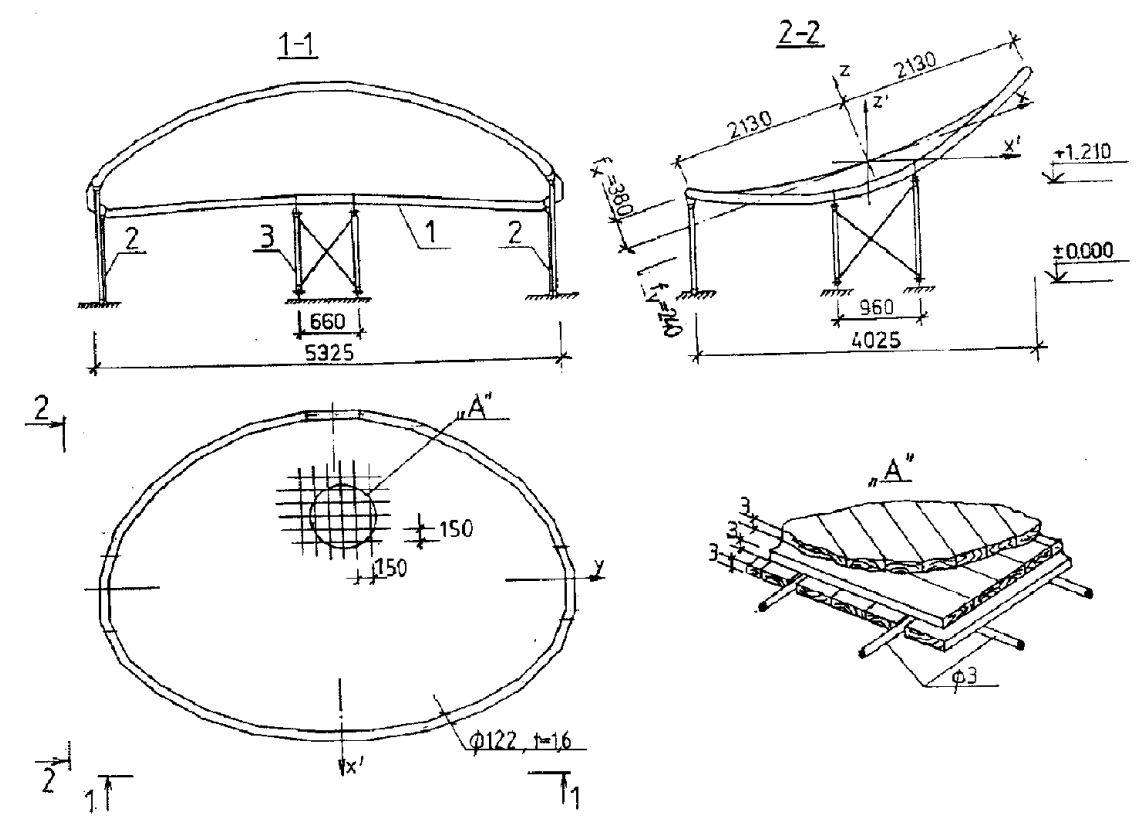

Fig. 2. Scheme of a roof shell model. 
(a)
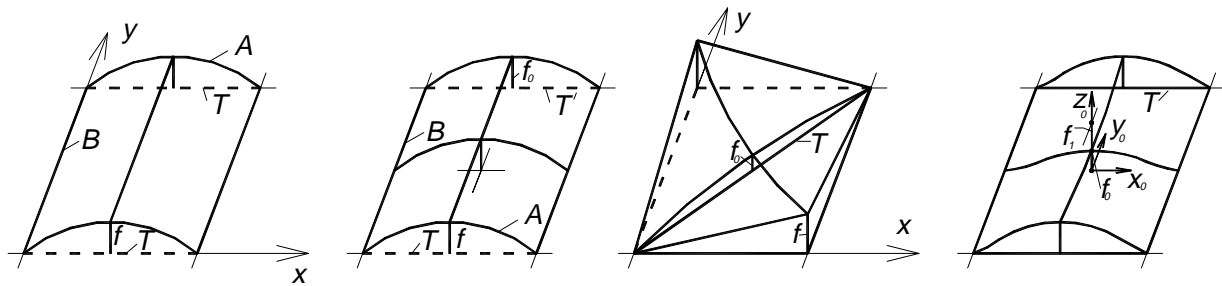

$$
z_{0}=f_{0}\left(1+\frac{f_{0} y_{0}^{2}}{f_{0} b^{2}}\right) \cos \frac{\pi}{2} \frac{x_{0}}{a}
$$

(b)

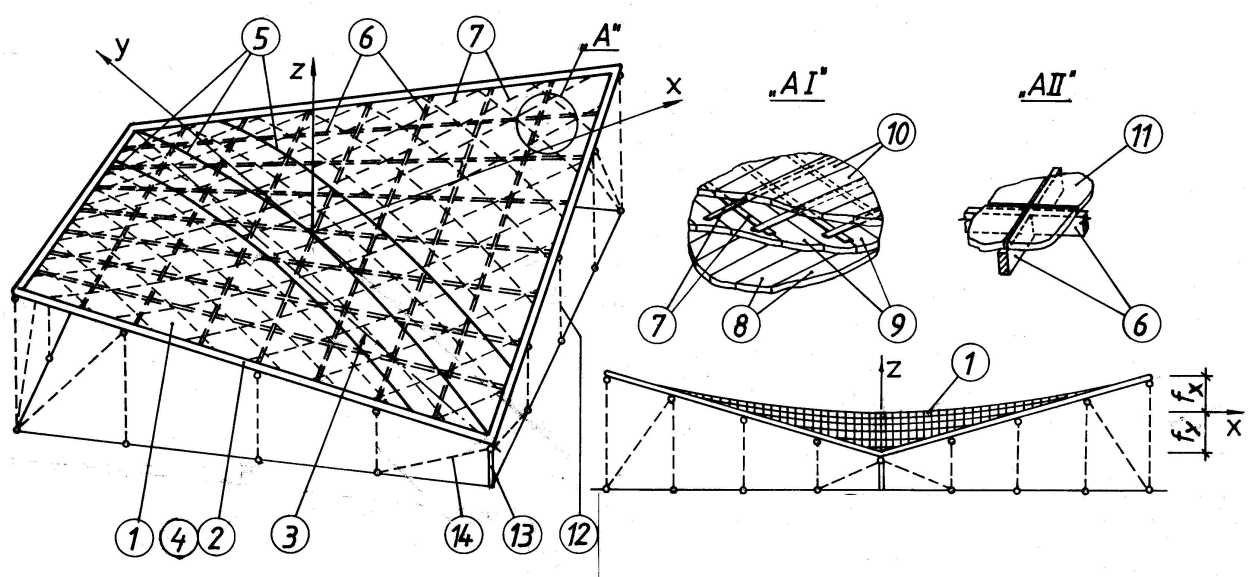

Fig. 3. Structural schemes of the shells: (a) timber shells; (b) structural elements of the tested shell: 1 - shell surface; 2, 4-edge beams; 3 -tie-rod; 5 -prestressed steel cables; 6 -ribs; 7 -glassreinforced plastic network; 8-10-shell boards; 11 - cladding on the ribs; 12 -posts; 13 - main columns; 14 - braces.

The main parameters of the timber shell models (Fig. 3b) and cable or cablecomposite structures (Fig. 1) are given in Table 1. The parameters of the roof shell model composed of a suspended prestressed cable network, layered timber shell and elliptical contour, with interconnected elements are given in Fig. 2. 
Table 1. Main parameters of the timber shell models

\begin{tabular}{|c|c|c|c|c|c|c|c|c|c|c|c|c|c|c|c|}
\hline \multirow[b]{2}{*}{$\frac{0}{z}$} & \multirow[b]{2}{*}{$\begin{array}{l}\frac{\tilde{\Xi}}{2} \\
\Xi \\
\tilde{\Xi} \\
. \bar{\Xi} \\
\tilde{\Xi} \\
\tilde{\Xi} \Xi\end{array}$} & \multirow[b]{2}{*}{ 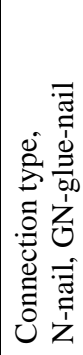 } & \multirow[b]{2}{*}{ 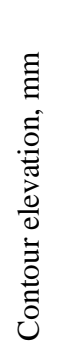 } & \multirow[b]{2}{*}{ 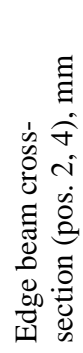 } & \multirow[b]{2}{*}{ 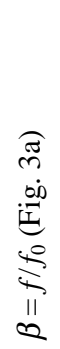 } & \multirow[b]{2}{*}{ 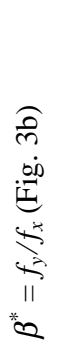 } & \multirow[b]{2}{*}{$\underset{\leftarrow}{\tilde{\Xi}}$} & \multirow[b]{2}{*}{$\begin{array}{l}\frac{\tilde{0}}{\vec{d}} \\
\frac{\vec{\sigma}}{4} \\
\dot{0} \\
\dot{z}\end{array}$} & \multirow[b]{2}{*}{ 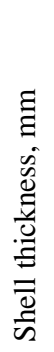 } & \multirow[b]{2}{*}{ 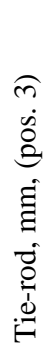 } & \multicolumn{5}{|c|}{ Structural elements } \\
\hline & & & & & & & & & & & $\begin{array}{l}n \\
\dot{0} \\
\stackrel{0}{ } \\
40 \\
\dot{0} \\
\dot{z}\end{array}$ & $\begin{array}{l}0 \\
\dot{0} \\
0\end{array}$ & $\begin{array}{l}\text { I } \\
\stackrel{1}{2} \\
\dot{0} \\
\dot{0}\end{array}$ & $\begin{array}{l}\stackrel{M}{2} \\
\dot{0} \\
\stackrel{0}{2}\end{array}$ & $\begin{array}{l} \pm \\
\dot{0} \\
\dot{0}\end{array}$ \\
\hline
\end{tabular}

Saddle-shape shells (types $H$ and $H^{\prime}$ )

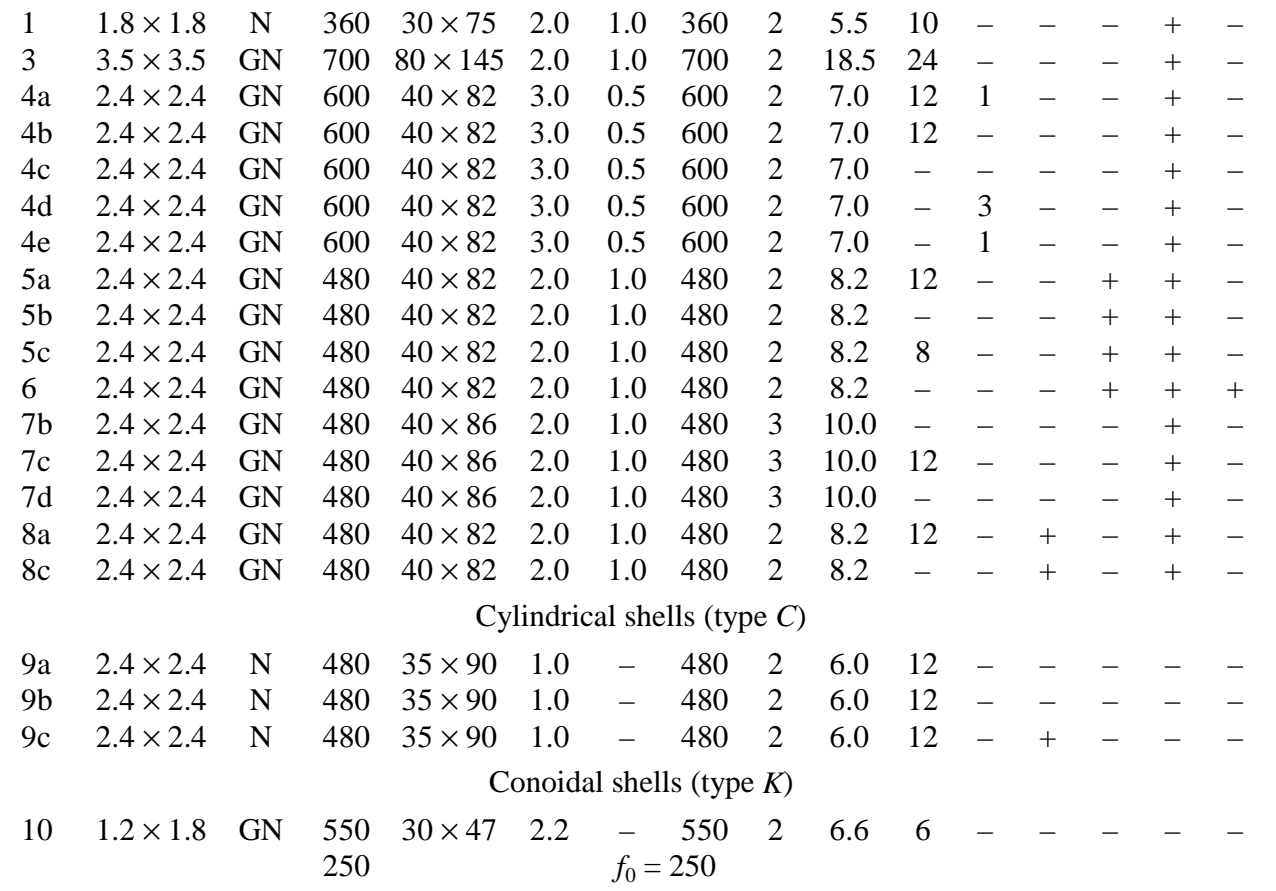

\section{TIMBER SHELLS}

\subsection{Experimental investigations}

The models were loaded with evenly and unevenly distributed vertical loads up to $6 \mathrm{kN} / \mathrm{m}^{2}$. Some models were loaded until collapse.

The following conclusions can be drawn from the experiments with timber shells.

$H$-type shells, when $\beta^{*}=f_{y} / f_{x}<1$, are preferable to usual hypars. For instance, when $\beta=3$ (Table $1, H^{\prime}$-type shell, model 4 ), vertical displacements, inner forces in the tie-rod (and, consequently, the longitudinal force), and also 
bending moments of the edge beam decrease nearly 1.2 times, thus simplifying the construction of the main bearing unit. Thus the $H^{\prime}$-type shells can also be used without the tie-rods, the work of the shell resembling that of a curved plate freely resting on 4 columns. Apart from that, vertical and horizontal displacements are substantially reduced as compared to hypars (cf. Table 1, model 4c).

If horizontal tie-rods cannot be used to restrict roof creeping, braces represented in Fig. 3b (pos. 14) can be applied, which take up also part of the forces from the edge beam.

When no tie-rod is used in saddle-shape shells with appropriate geometry $(\beta \geq 2)$, they work normally. However, square and diamond-shaped shells are recommended to construct without tie-rods only in exceptional cases. The tierods should be placed in the wall plane, since inner forces and displacements are greater than in structures with horizontal tie-rods or counterforts.

Strengthening of the $H$-type shells by prestressed cables (Fig. 3b, pos. 5) or by glass-reinforced plastic network (pos. 7) yields an inconsiderable effect (a substantial reduction of inner forces in the tie-rod occurs, but deflections are insignificantly affected). Prestressed cable network is primarily used to obtain the desired surface through prestressing the cables under free mutual sliding, used as a shutter. A large-span structure is under construction in which the network and the thin timber shell, resting upon the prestressed steel cable network, work together, the latter being of increased importance. The effect of the cable network is taken into account in calculations.

Saddle-shaped shells work well at considerable deflections and have increased stability. For instance, $H$ - and $H^{\prime}$-type shells with relative thickness $t / 2 a=$ $1 / 200-1 / 400$ are capable of carrying heavy loads $\left(p=4-6 \mathrm{kN} / \mathrm{m}^{2}\right)$ without loss of total stability. $C$-type shells are to be strengthened by arched and longitudinal ribs to ensure stability. $H$-type thin timber shells behave normally in spite of great displacements $(1 / 150-1 / 200)$. However, too great changes in the geometry (1/50 and more) are not allowed in this case either, for it may bring about an increase in bending moments and failure of the structure.

At great deflections, produced by the local stability loss of the membrane (the aftercritical work) and by other reasons, the arm of the inner force of the tie-rod in the region of lower corners and bending moments is increased. Therefore shells with relative thickness of $1 / 320$ and less as well as the $H$-type shell have to be strengthened by ribs to ensure the required bearing capacity.

It should be noted that for $H$-type shells reaching the ultimate load is the relevant mode of strength loss, while for $C$-type shells it is reaching the buckling load.

Thus it is necessary to take into account deformations of the after-effect which are noticeable when shells are maintained under increased temperature and moisture content. For example, faulty construction of a roof and caused by that moisture content of the timber, amounting to $25-40 \%$, the hampered drying out and high maintenance temperature of $50-60^{\circ} \mathrm{C}$ produced an additional deflection increase of $120 \mathrm{~mm}$ over the period of 5 years in $H$-type two-layered board shells 
$\left(10 \times 10 \mathrm{~m}, t=50 \mathrm{~mm}\right.$, dead weight $p=1.5 \mathrm{kN} / \mathrm{m}^{2}$, initial deflection $\left.40 \mathrm{~mm}\right)$. It was necessary to prevent further increase of the deflections with additional braces.

\subsection{Numerical analysis}

Flat shells presented in Fig. 3a were examined. To determine the stress-strain state of board-layered $H$-type timber shells, the following methods can be used.

1. Membrane theory and its different modifications ensured determination of the longitudinal forces of the contour beam and tie-rod with satisfactory accuracy. Board surface forces were evaluated approximately.

2. A calculation method was used where shell layers were replaced by the corresponding convex and concave arches. The equation for the potential energy of deformation was derived and using the Castiliano theorem a system of equations was obtained to determine the unknown forces $\left[{ }^{1}\right]$. To achieve sufficient accuracy, in each direction (in each layer) from 5 to 9 arches were used in the calculation scheme. In such an approximation, which is justified by the experimental data, forces in the shell were determined both for the structures with and without tierods.

3. More accurate results have been reached using the geometrically non-linear moment theory in the method of final differences $\left[{ }^{2,3}\right]$, taking into account the deformation of the contour beam. At the same time it should be noted that physical non-linearity caused by the pliability of the connections cannot be totally neglected, and shell deformations caused by the after-effect of the material are substantial.

4. A system based on FEM was also used. Three-layered timber board shells had a thickness of $75 \mathrm{~mm}$. Effective deformation modulus of the membrane was $5000 \mathrm{MPa}$, Poisson's ratio 0.5. Elastic modulus of the edge elements was $10000 \mathrm{MPa}$, depth $800 \mathrm{~mm}$, and width $180 \mathrm{~mm}$. Dimensions of the shell were $18 \times 18 \mathrm{~m}$, elevation of the upper points $f=2 f_{0}=1 / 5$ of the span $(3.6 \mathrm{~m})$. Crosssection of the tie-rod was $5.6 \times 10^{3} \mathrm{~mm}^{2}$. Loading was $2.5 \mathrm{kN} / \mathrm{m}^{2}$ (displacements were determined at $2.0 \mathrm{kN} / \mathrm{m}^{2}$ ). For calculation purposes, the shell was divided by a network of $9 \times 9$ into 162 triangular elements with the cathetus length $2 \mathrm{~m}$. The contour beam and arch, respectively, were divided into 9 elements.

The conclusions based on the calculations are the following.

$H$ - and $S$-type shells have maximum vertical displacements. $S$-type shells are subjected to maximum horizontal displacements. Hence, its contour requires much greater rigidity in the horizontal plane.

About $90 \%$ of the total vertical loads of the hypar $(H)$ is transferred to 2 columns at lower corners.

The inner forces of the tie-rod in the hypar exceed about twice the total inner forces of tie-rods in the cylinder and are much greater than those for any other shell type.

In $H$ - and $S$-type shell contours, longitudinal forces are the greatest. It should be emphasized that the division of the shell and contour into final elements of $2 \mathrm{~m}$ 
affects the distribution of inner forces at shell corners. To obtain more accurate results, smaller network pitch (at least $0.1-0.2 \mathrm{~m}$ ) is required when forming the FE grid in the corner region. It is also desirable to consider inhomogeneity of the board-layered shell, but in thin shells this would not have an essential effect. $\mathrm{H}$ type shells with hinged connections between beams, arches, and supports were also analysed. In this case an increase by 1.3 times of the bending moments of the contour was observed. Nevertheless, it should be noticed that because of continuity of the membrane, substantial moments occurred in the contour beam.

$C$-, $K$-, and $S$-type shells have tensioned contour beams and thus strengthening them with prestressed cables can have a favourable effect on their work (it is also proved by the tests with a $K$-type shell model).

In a $H^{\prime}$ - type shell where $\beta=2$, inner forces of the tie-rod, those of the contour, and deflections decrease by $20 \%$, while the maximum bending moment of the contour remains unchanged.

Calculations were also made for temporary loads applied on one half of the span. In this case, considerable changes in the qualitative picture of the displacements and inner forces were observed. Maximum values of displacements grow, depending on the shell type, from 1.3 to 2 times, but do not exceed 1/180 of the span. The inner forces partly change the sign, maximum moments increase from 1.5 to 3 times, but the maximum longitudinal forces decrease about 1.5 times.

For shells supported by 4 columns, the stress-strain state, especially the forces in tie-rods, also depend on the bending rigidity of columns.

Calculation results are relatively close to the experimental data. It should be noted that deflections of similar models or erected timber shells can exceed the calculated ones up to twice. The program, which considers also geometrical and physical non-linearity, gives more accurate results. However, pliability and structural imperfections cannot be taken into account.

It should be underlined (and is proved also with the tests) that $H$ - and $S$-type shells have increased stability and their critical loads exceed $2.5 \mathrm{kN} / \mathrm{m}^{2}$. At the same time, when determining the bearing capacity of $C$ - and $K$-type shells, stability considerations are of prime importance; critical loads of $C$ - and $K$-type shells do not exceed $0.7-1.0 \mathrm{kN} / \mathrm{m}^{2}$ and when $p=2.5 \mathrm{kN} / \mathrm{m}^{2}$, they are to be strengthened by ribs.

\subsection{Design and erection of timber shells}

Constructions of timber shell roofs have been worked out by Estonian design organisations and a number of these shells (about 30 roofs) have been erected. Some shells have been in exploitation for thirty years. Full-scale investigations of their behaviour under different maintenance conditions are being conducted. Figure 4 depicts the interior of a composite timber shell.

During 7-30 years of maintenance, the described timber shells have not revealed any special problems, except when waterproofing was damaged (which caused appearance of fungi). 


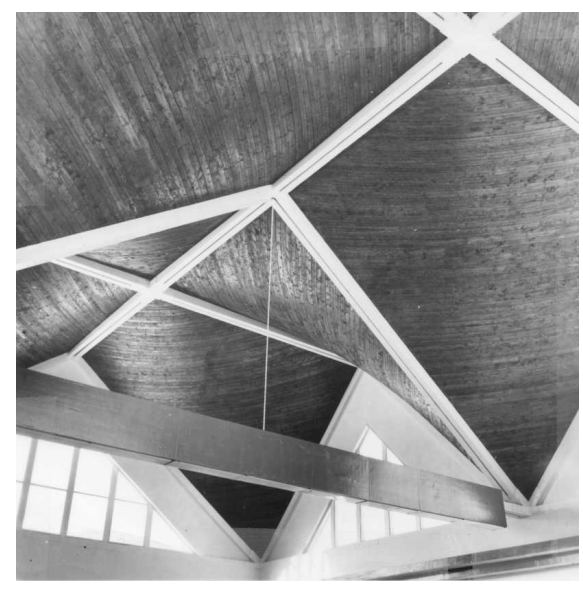

Fig. 4. Interior of a composite timber shell.

\section{CABLE AND CABLE-COMPOSITE ROOF SYSTEMS}

\subsection{Experimental investigation}

To study the work of the cable systems, different models were built and tested. This article focuses on the behaviour of the models shown in Figs. 1a and 2.

Model parameters of the first group (Fig. 1a, type 1 - without cladding, type 2 - with cladding from plywood plates, and type 3 - with steel plates) were as follows: dimensions in plan $1.768 \times 1.768 \mathrm{~m}$; the edge element consisted of a steel tube of $33.0 \mathrm{~mm}$ in diameter with $t=3.0 \mathrm{~mm}$; four corners were supported in the vertical direction, steel tie-rod diameter was $12 \mathrm{~mm}, f=490 \mathrm{~mm} ; 8$ highstrength wire cables of $1.6 \mathrm{~mm}$ diameter were used in each direction; cable pitch was about $278 \mathrm{~mm}, \beta=0.75$. In the initial state, cable network surface was formed by cable prestressing with mutual sliding, followed by fixing network knots and mounting panels. Ratio of prestressing forces in cables $T_{y}^{0} / T_{x}^{0}=0.425 / 0.32 \mathrm{kN} / \mathrm{m}$. Roof cladding was made of three-layer plywood $(t=4 \mathrm{~mm})$ or steel $(t=0.35 \mathrm{~mm})$ plates, with edges strengthened by $8 \mathrm{~mm}$ ribs. Plates were attached by bolts to network knots and the contour beam through central steel knot elements by bolts.

Models were loaded both evenly all over the surface (live load $0.25-2 \mathrm{kPa}$, dead weight $0.25-0.5 \mathrm{kPa}$ ) and with unevenly distributed or local loads $(0.08-$ $0.16 \mathrm{kN})$ and dead weight of the contour $(0.41 \mathrm{kN} / \mathrm{m})$.

The model of the second group of structures (Fig. 2, type 4 without a shell, type 5 with a shell), without a tie-rod, is a hypar-shaped suspension roof inside an inclined elliptical contour, where central points of cross-sections of the contour were located on a spatial curve, formed by the intersection of two surfaces:

$$
\text { hypar } z=f_{x} \cdot x^{2} / a^{2}-f_{y} \cdot y^{2} / b^{2},
$$




$$
\text { elliptical cylinder } x^{2} / a^{2}+y^{2} / b^{2}=1,
$$

where $a=2.13$ and $b=2.663 \mathrm{~m}$. The surface part (cladding) of the roof model consisted of a 3-layered timber shell made from boards that rested on prestressed cable network and was connected to the contour and the cable network. Highstrength wire cables of $3.0 \mathrm{~mm}$ were used in each direction. Prestressing forces were $T_{x}^{0}=0.86$ and $T_{y}^{0}=2.04 \mathrm{kN} / \mathrm{m}$. The contour consisted of straight sections of steel tubes and rested on three plain supports. Hinge joints were used to connect the columns of the supports, the contour tube, and the foundation. This connection allowed free displacements of the supported parts in the direction, perpendicular to the planes of the supports. Longitudinal ribs with the crosssection of $1.6 \times 20 \mathrm{~mm}$ for fixing load-carrying and damping cables and the timber shell were welded to the inner side of the contour tube. Other parameters are shown in Fig. 2.

Different gravitational loads were used, which were either uniformly distributed over all the roof surface or over the half or quarter of the surface. The empty tube was filled with concrete. Concrete filling was used to reduce vertical displacement of the front freely suspended part. However, it is sufficient to use a filling only in some parts of the contour tube. These parts will resist to forces as composite steel-concrete members. The static work of the roof was examined and dynamic parameters were determined. A 1:100 scale roof model was tested in a wind tunnel to determine the coefficients of wind pressure $\left[{ }^{4}\right]$. This particular structure was designed for the acoustic screen of the song festival tribune in Tartu, Estonia. The scale of the model was 1:10.

All types of the studied roof systems had a relatively thin roof structure and a contour of high slenderness.

\subsubsection{Some test results}

\section{First group of models}

Loads evenly distributed all over the shell surface. Plywood plates used for the under-roof structure caused a considerable redistribution of inner forces. As a result, increments of inner forces in all carrying cables were almost equalized. Increments of inner forces in central cables decreased by $70 \%$ with the application of a tie-rod, but without it by $50 \%$, as compared to the model without a cladding. Steel plates had a still greater equalizing effect on the inner forces between carrying cables. It is interesting to note that increments of inner forces in central bearing cables were even smaller than in edge cables.

In models without horizontal tie-rod, damping cables could, to some extent, replace it. As a result, inner forces showed an increase for all types of claddings. Plate cladding improved the condition: with plywood plates $50 \%$ and with steel plates even $80 \%$ of the prestressing forces remained. All types of the cladding construction reduced vertical displacements of the central point of the cable network, as compared to those with no cladding (with a tie-rod and steel plates - 
by $55 \%$, without a tie-rod and steel plates - by $35 \%$ ). A decrease of about $40 \%$ of the contour creep was observed in the case of cladding.

Bending moments caused by the live and dead load on the vertical contour plane exceeded about five times those observed in the horizontal plane, but contour parameters were still determined through the load caused by cable prestressing, where considerable bending moments were observed mainly in the horizontal plane.

Non-symmetrical loads. Both plate types led to a substantial redistribution of inner forces in cables, resulting in more even distribution of the latter. At the same time, a 50-60\% reduction of an absolute increase in the inner forces within cables was observed as compared to the cable network with no plates.

Local loads. A notable effect of plates on the reduction of local deflections on the roofing was observed, which is also significant to avoid major deformation and to maintain an integral roofing.

Application of a tie-rod. A good deal of prestressing force was preserved due to panels, which is mainly observed with steel plates. This led also to an increase in dynamic stability. Steel plates reduced the amplitude of shock-load vibrations up to $30-70 \%$, increased the frequency by $30-50 \%$ and accelerated vibration damping.

Contour without a tie-rod. Inner forces exceeded about 5-10 times and roofing displacements several times those present with a tie-rod. But the structure still had a working capacity.

It should be noted that in the case of thrustless (without a tie-rod) contour, aerodynamic sensitivity is considerably reduced, since in the loading process the rigidity of the structure increases, while by the application of a tie-rod it decreases.

\section{Second group of models}

Figure 5 shows the results of static tests. As a rule, number 1 means cable network (without a shell, type 4), number 2 -network plus timber shell connected to the network and the contour (type 5). Diagrams in Fig. 5 demonstrate increments of the inner forces in cables, both in the carrying (section 1-1, Fig. 2) and damping (section 2-2) cables that occur by loading of the roof.

(a)

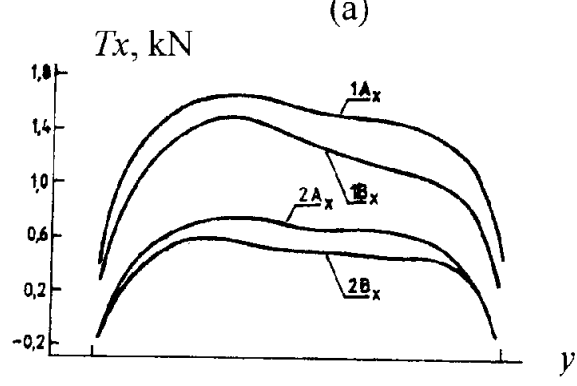

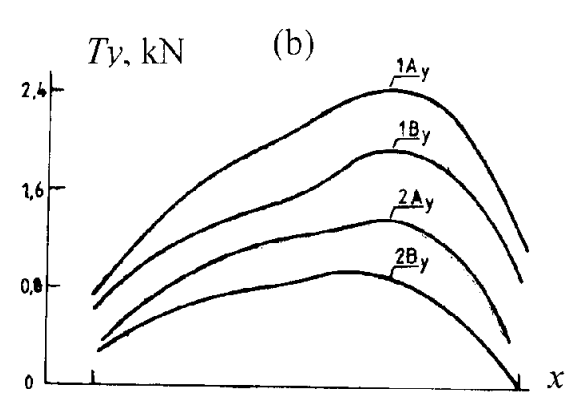

Fig. 5. Increments of the inner forces in cables: (a) loading uniformly distributed over the surface; (b) dead load plus uniformly distributed live load on one half of the roof surface. 
Dynamic parameters were determined in the conditions of damped free vibrations of the structure $\left[{ }^{5}\right]$. The distribution of wind pressure coefficients was determined in a wind tunnel for different orientations of the model $\left[{ }^{4}\right]$.

The examined roof types 4 and 5 are freely deformable in directions $X$ and $Y$ (Fig. 2). Usually counterforts or tie-rods in direction $Y$ are used and therefore by loading prestressing forces in the damping cables decrease. In this case, because of free deformation of the contour in direction $Y$, damping cables act as tie-rods, preventing large displacements. Consequently, their tension grows. Relatively small forces are sufficient to prestress (to create) the initial network surface. By loading, in cables tension forces in both directions increase, except for some outer cables. At the same time, increments of the tension in damping cables exceed those in the carrying cables approximately by $40 \%$.

The bearing capacity (strength, stiffness) of the roof will increase considerably when the network is covered with a timber shell, formed by 2 to 3 layers of nailed boards and connected with the nodes of the network and with the contour (Fig. 5). The influence of the cladding on the static and dynamic properties of the roof depends on the stiffness that the cladding adds to the structure.

By roof type 5, tension stiffness of the shell roof surface increased only 1.6-2 times. Tension increments of carrying cables were reduced twice, the deflection of the roof surface -1.7 times, and the tension of damping cables increased 1.8 times. Because of the stiffness of the timber shell, horizontal displacements of the contour in direction $X$ decreases about $25 \%$ and in $Y$ direction about $40 \%$. At the same time, upward displacements of the front part of the contour (Fig. 6a) increase. The latter undesired factor can be compensated with an additional mass in the front part of the contour. Moderate filling of concrete into the middle of the front part of the tubular contour brings about a decrease in the bending moments and displacements, but it is accompanied by an increase in cable forces. Loading on the lower (back side) half of the roof surface proves most unfavourable.

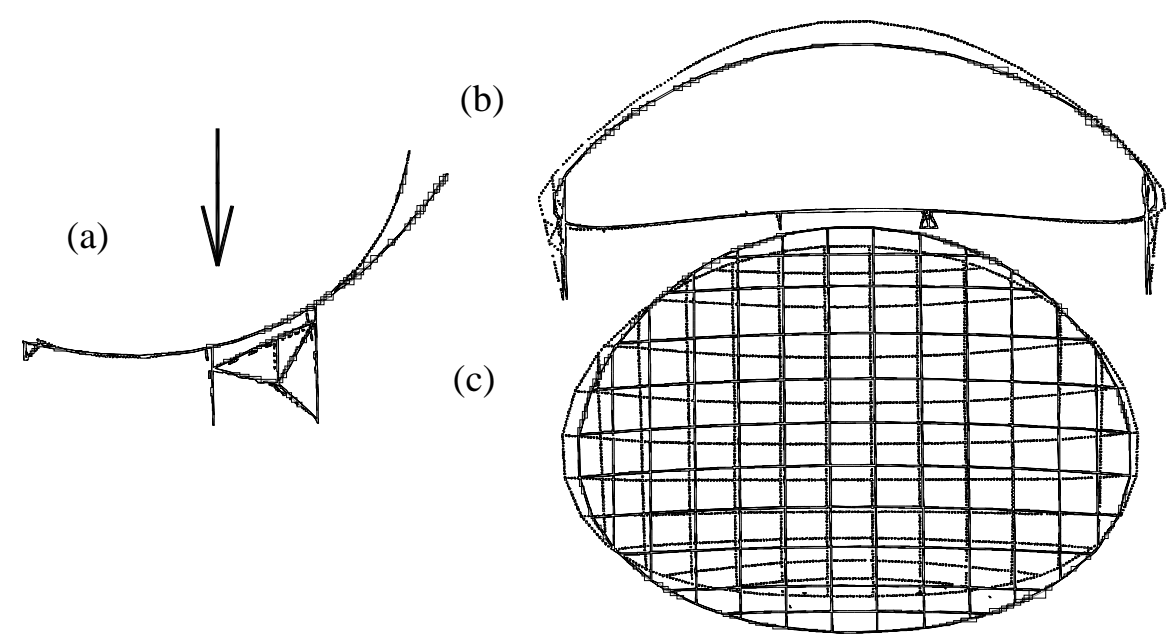

Fig. 6. Deformations of the roof structure: (a) side view; (b), (c) elevation and plan. 
We could observe that the cladding connected to the contour and network brings about a decrease in the amplitude and a rise in vibration frequencies. The lowest natural frequency of the type 5 structure is, to a great extent, determined by the mass of the freely suspending front part of the contour. Thus, to design a real structure, it is necessary to consider that an increase in the contour stiffness with a simultaneous increase of its own weight does not necessarily lead to an increase in the dynamic stiffness of a roof. The value of the logarithmic decrement varies between 0.13 and 0.25 . The natural frequency for a roof without a shell was $2.45 \mathrm{~Hz}$ and with a shell $-3.0 \mathrm{~Hz}\left[{ }^{5}\right]$. In a real structure, it is 0.78 and $0.95 \mathrm{~Hz}$, respectively.

We have to consider that the effect of the cladding in the real structure decreases because part of the loading (the weight of the cladding) will be applied to the roof before connecting it to the contour.

\subsection{Numerical analysis}

The action of the cladding (panels) of the roof is commonly neglected when calculating inner forces and displacements for the bearing part of a suspension roof, i.e., the cable network and contour beam. In calculations influence of the cladding is simply taken into account as dead load of the structure $\left[{ }^{6-10}\right]$.

A special discrete method was developed to analyse suspension saddle-shaped roofs, based on the non-linear theory (large displacements, where also yielding of the connections is possible), which enables us to consider tension-compression and shear stiffness of the cladding. Equations and results are given in $\left[{ }^{11}\right]$.

To determine the geometry of a saddle-shape surface, especially if $\beta^{*}=f_{y} / f_{x} \neq 1$, the condition of equilibrium of a non-loaded knot (Fig. 7a) can be used. The location of a certain knot $i, k$ is determined by the radius vector $r_{i, k}$, using the formula

$$
T_{0 i}\left[\frac{\bar{r}_{i, k+1}-\bar{r}_{i, k}}{\left|\bar{r}_{i, k+1}-\bar{r}_{i, k}\right|}+\frac{\bar{r}_{i, k-1}-\bar{r}_{i, k}}{\left|\bar{r}_{i, k-1}-\bar{r}_{i, k}\right|}\right]+T_{0 k}\left[\frac{\bar{r}_{i+1, k}-\bar{r}_{i, k}}{\left|\bar{r}_{i+1, k}-\bar{r}_{i, k}\right|}+\frac{\bar{r}_{i-1, k}-\bar{r}_{i, k}}{\left|\bar{r}_{i-1, k}-\bar{r}_{i, k}\right|}\right]=0,
$$

where $T_{i}^{0}, T_{k}^{0}$ are prestressing forces and $m_{i, k}=T_{k}^{0} / T_{i}^{0}$ is the ratio of prestressing forces.

Contour beam coordinates are taken as known values. Ratios $m_{i, k}$ can arbitrarily be predetermined only for all knots of the two crossing cables $\left[{ }^{12}\right]$.

To determine the state of strain and stress of the prestressed or nonprestressed loaded cable network, taking into account roof cladding and contour beam deformation, the discrete method described in $\left[{ }^{11,13,14}\right]$ can be used.

A general system of equations (Fig. 7b) for displacements of the loaded knots, where prestressing forces of the cable network and the diagonal elements (not prestressed) are taken into account, is expressed in the following form: 
(a)

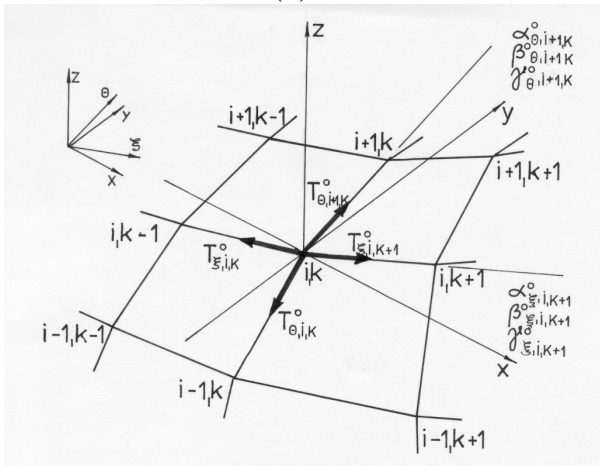

(b)

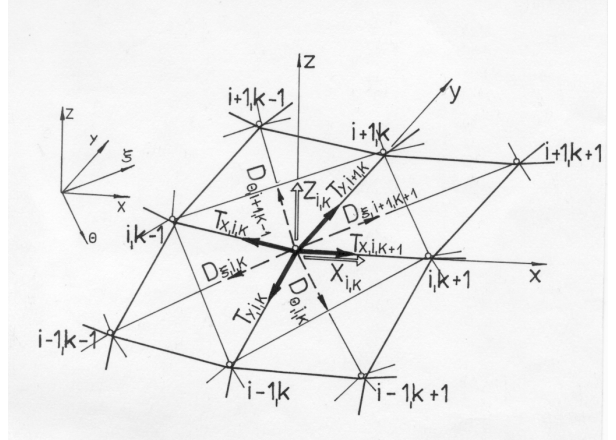

Fig. 7. Calculation schemes of the network knots of the roof system: (a) prestressed, not loaded, without cladding elements; (b) with the cladding elements $D_{i, k}$.

$$
\begin{aligned}
& -T_{x, i, k}^{0} L_{x, i, k}+T_{x, i, k+1}^{0} L_{x, i, k+1}-\Psi_{x, i}\left(G_{x, i, k}-G_{x, i, k+1}\right)-\Psi_{\xi, i, k} R_{\xi, i, k} A_{\xi, i, k} \\
& -\Psi_{\theta, i, k} R_{\theta, i, k} A_{\theta, i, k}+\Psi_{\xi, i+1, k+1} R_{\xi, i+1, k+1} A_{\xi, i+1, k+1}+\Psi_{\theta, i+1, k-1} R_{\theta, i+1, k-1} A_{\theta, i+1, k-1} \\
& +X_{i, k}=0, \\
& -T_{y, i, k}^{0} M_{y, i, k}+T_{y, i+1, k}^{0} M_{y, i+1, k}-\Psi_{y, k}\left(G_{y, i, k}-G_{y, i+1, k}\right)-\Psi_{\xi, i, k} R_{\xi, i, k} B_{\xi, i, k} \\
& -\Psi_{\theta, i, k} R_{\theta, i, k} B_{\theta, i, k}+\Psi_{\xi, i+1, k+1} R_{\xi, i+1, k+1} B_{\xi, i+1, k+1}+\Psi_{\theta, i+1, k-1} R_{\theta, i+1, k-1} B_{\theta, i+1, k-1} \\
& +Y_{i, k}=0, \\
& -T_{x, i, k}^{0} N_{x, i, k}+T_{x, i, k+1}^{0} N_{x, i, k+1}-\Psi_{x, i}\left(J_{x, i, k}-J_{x, i, k+1}\right)-T_{y, i, k}^{0} N_{y, i, k}+T_{y, i+1, k}^{0} N_{y, i+1, k} \\
& -\Psi_{y, k}\left(J_{y, i, k}-J_{y, i+1, k}\right)-\Psi_{\xi, i, k} R_{\xi, i, k} C_{\xi, i, k}-\Psi_{\theta, i, k} R_{\theta, i, k} C_{\theta, i, k} \\
& -\Psi_{\xi, i+1, k+1} R_{\xi, i+1, k+1} C_{\xi, i+1, k+1}+\Psi_{\theta, i+1, k-1} R_{\theta, i+1, k-1} C_{\theta, i+1, k-1}+Z_{i, k}=0,
\end{aligned}
$$

where

$$
\begin{aligned}
& \Psi_{\theta, i, k}=E_{\theta} \Omega_{\theta, i, k}, \Psi_{\xi, i, k}=E_{\xi} \Omega_{\xi, i, k}, \\
& R_{\xi, i, k}=\Delta l_{Z, i, k} /\left[l_{\xi, i, k}^{0}\left(l_{\xi, i, k}^{0}+\Delta_{\xi, i, k}\right)\right], \\
& l_{\xi, i, k}^{0}=\left[\left(a_{\xi, i, k}^{0}\right)^{2}+\left(b_{\xi, i, k}^{0}\right)^{2}+\left(c_{\xi, i, k}^{0}\right)^{2}\right]^{1 / 2}, a_{\xi, i, k}^{0}=x_{i, k}^{0}-x_{i-1, k-1}^{0}, \\
& b_{\xi, i, k}^{0}=y_{i, k}^{0}-y_{i-1, k-1}^{0}, c_{\xi, i, k}^{0}=z_{i, k}^{0}+z_{i-1, k-1}^{0}, \\
& A_{\xi, i, k}=a_{\xi, i, k}^{0}+u_{i, k}-u_{i-1, k-1}, \\
& B_{\xi, i, k}=b_{\xi, i, k}^{0}+v_{i, k}-v_{i-1, k-1}, C_{\xi, i, k}=c_{\xi, i, k}^{0}+w_{i, k}-w_{i-1, k-1}, \\
& \Delta l_{\xi, i, k}=\left[a_{\xi, i, k}^{0}\left(u_{i, k}-u_{i-1, k-1}\right)+b_{\xi, i, k}^{0}\left(v_{i, k}-v_{i-1, k-1}\right)+c_{\xi, i, k}^{0}\left(w_{i, k}-w_{i-1, k-1}\right)\right] / l_{\xi, i, k}^{0},
\end{aligned}
$$




$$
\begin{aligned}
& R_{\theta, i, k}=\Delta l_{\theta, i, k} /\left[l_{\theta, i, k}^{0}\left(l_{\theta, i, k}^{0}+\Delta l_{\theta, i, k}^{0}\right)\right], \\
& A_{\theta, i, k}=a_{\theta, i, k}^{0}+u_{i, k}-u_{i-1, k+1}, \\
& B_{\theta, i, k}=b_{\theta, i, k}^{0}+v_{i, k}-v_{i-1, k+1}, \\
& C_{\theta, i, k}=c_{\theta, i, k}^{0}+w_{i, k}-w_{i-1, k+1}, \\
& \Delta l_{\theta, i, k}=\left[a_{\theta, i, k}^{0}\left(u_{i, k}-u_{i-1, k+1}\right)+b_{\theta, i, k}^{0}\left(v_{i, k}-v_{i-1, k+1}\right)+c_{\theta, i, k}^{0}\left(w_{i, k}-w_{i-1, k+1}\right)\right] / l_{\theta, i, k}^{0}, \\
& a_{\theta, i, k}^{0}=x_{i, k}^{0}-x_{i-1, k+1}^{0}, \\
& b_{\theta, i, k}^{0}=y_{i, k}^{0}-y_{i-1, k+1}^{0}, \\
& c_{\theta, i, k}^{0}=z_{i, k}^{0}-z_{i-1, k+1}^{0}, \\
& l_{\theta, i, k}^{0}=\left[\left(a_{\theta, i, k}^{0}\right)^{2}+\left(b_{\theta, i, k}^{0}\right)^{2}+\left(c_{\theta, i, k}^{0}\right)^{2}\right]^{1 / 2}, \\
& D_{\xi, i, k}=\Delta l_{\xi, i, k} \Psi_{\xi, i, k} / l_{\xi, i, k}^{0}, D_{\theta, i, k}=\Delta l_{\theta, i, k} \Psi_{\theta, i, k} / l_{\theta, i, k}^{0} .
\end{aligned}
$$

Here $D_{\xi, i, k}$ and $D_{\theta, i, k}$ are inner forces of the diagonal elements located in directions $\xi$ and $\theta$, respectively.

When using the described method it is necessary to insert the displacements of the contour in the equations. It is used for the iteration process to solve the whole problem. Thus in the first stage inner forces of the cables are determined for an absolutely rigid contour. Displacements of the real contour for the second stage are determined with the forces of the near contour sections of cables of the first stage. The process continues until it converges. As a rule, 3-4 steps are sufficient.

Calculation results of the suspended cable systems, when substituting the cladding with the prestressed cable network and the contour beam of the roof, the longitudinal inner forces, bending moments of the contour beam (in the corresponding cases also inner forces of tie-rods) as well as deflections of the sheathing part of the shell were determined with satisfactory accuracy (differences between calculation and tests were from 3 to 20\%).

Various universal FEM program systems, such as TPS-10, ANSYS and Lyra were also used to analyse roof types 4 and 5 . We analysed the behaviour of the roof by three types of back supports, consisting of two columns. It is interesting to note that by the supports, not allowing horizontal displacements in the plane of back supports (Fig. 2, direction Y), large horizontal forces caused by the deformation of the flat contour arc between them arose between the supports. So we had to use one of the support columns as a pin-ended column. Calculation results (qualitative picture) of deformations of the roof structure are shown in Fig. 6.

\subsection{Conclusions}

Suspension roof cladding - timber shell, steel panels, etc., connected to the network and to the contour, increases the rigidity and the carrying capacity of the 
roof and contributes to a more even distribution of the inner forces between cables. Thus, additional use of the cladding is of major importance. A cladding raises the dynamic stability, i.e. reduces the amplitude of vibrations and increases natural frequency.

\subsection{Design and erection of a composite roof shell}

The hypar-shaped composite suspension roof inside an inclined elliptical contour described in section 3.1 (model type 5, Fig. 2) was designed for the acoustic screen of the song festival tribune in Tartu, Estonia, by the design organisation "Eesti Projekt". Professor V. Kulbach and the author of this paper were authors of the roof. The structure was erected in 1994 (Fig. 8).

Main dimensions of the roof are: $2 a=42 \mathrm{~m}, 2 b=54 \mathrm{~m}$, height of the highest point of the front contour arch $-27 \mathrm{~m}$. The diameter of the contour steel tube is $1220 \mathrm{~mm}$ with a thickness of $16 \mathrm{~mm}$, diameter of the prestressed network cables (round steel bars) is $30 \mathrm{~mm}$ with the pitch of $1.5 \mathrm{~m}$.

A three-layer nailed timber shell was constructed upon cables from boards with a thickness of $85 \mathrm{~mm}$. The timber shell was connected to the contour and to the cable network knots. The front part of the contour arc was filled with concrete to decrease upwards deflections at roof loading. Side (supported) areas of the tubular contour were also filled with reinforced concrete to increase the carrying capacity of these parts. Roof covering was made from Sarnafil.

\subsection{Maintenance of the structure}

The behaviour of the structure was observed (monitored) during nine years. Increments of deflections took place because of after-effects of the timber shell, as we could suppose on the basis of numerical analysis. Stiffness of the timber shell decreases and load is transferred partly to the cables. Increase of the deflections in time is shown in Fig. 9. The first big deformations took place by removing the mounting towers from under the front contour of the arch.

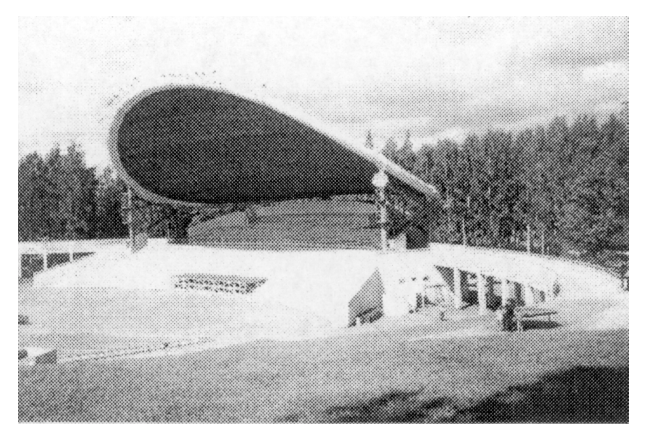

(a)

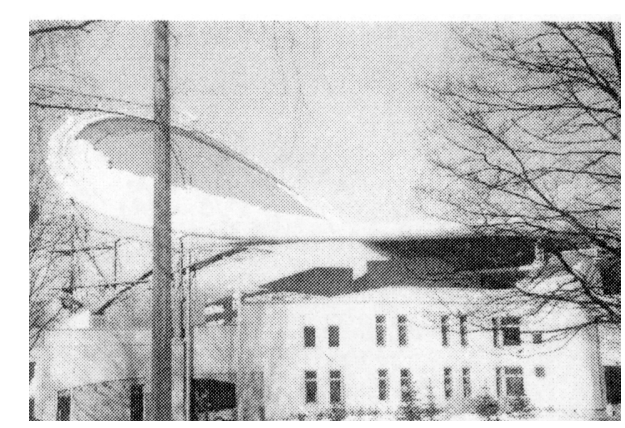

(b)

Fig. 8. Front (a) and side (b) views of the acoustic screen of Tartu song festival tribune. 


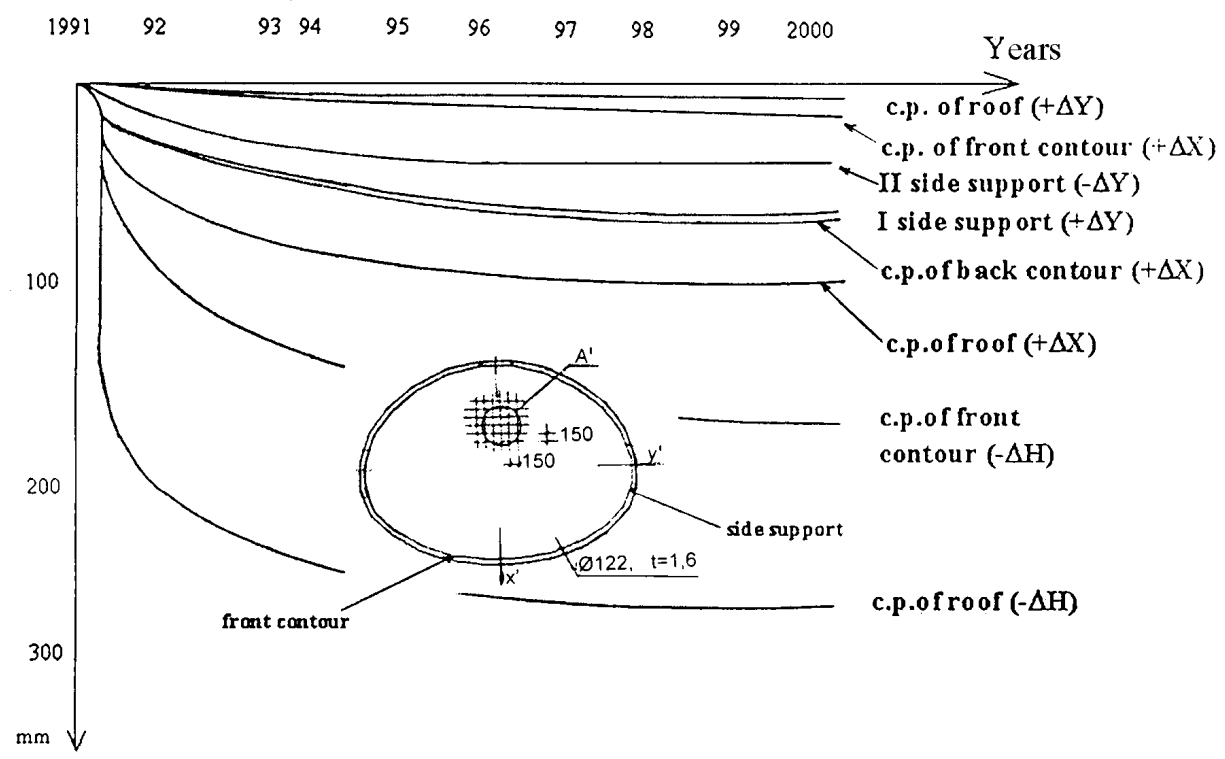

Fig. 9. Development of the deflections of the roof in time.

Unexpectedly, in winter, by close to zero temperatures, the song festival tribune gathered a $300 \mathrm{~mm}$ snow layer on the upper strongly inclined roof area and slippery Sarnafil surface. Some days later, this snow (about 30 tons) fell (Fig. 8b) on the lower part of the roof as avalanche, causing a mild impact.

\section{REFERENCES}

1. Õiger, K. and Just, E. On calculation of saddle-shape crossing bar structure by the energy method. Trans. Tallinn Polytechn. Inst., 1984, No. 575, 81-90 (in Russian).

2. Õiger, K. and Rattasepp, T. Die Rechnung der Holzhyparschale mit der Berücksichtigung der grossen Durchbiegung. Trans. Tallinn Polytechn. Inst., 1983, No. 551, 45-46 (in Russian).

3. Õiger, K. and Rattasepp, T. Some results of calculating timber hypars. Trans. Tallinn Polytechn. Inst., 1984, No. 571, 55-65 (in Russian).

4. Hendrikson, V., Õiger, K. and Talvik, I. Wind-tunnel studies of Tartu song festival complex. Trans. Tallinn Techn. Univ., 1989, No. 691, 59-68.

5. Õiger, K. and Talvik, I. Determination of dynamic characteristics of a saddle-shaped suspension roof. Trans. Tallinn Techn. Univ., 1990, No. 721, 32-37.

6. Structural Engineering Handbook (Gaylord, E. H. and Gaylord, Ch. N., eds.), McGraw-Hill, New York, 1990.

7. Moskalev, N. S. Suspension Roof Constructions. Strojizdat, Moscow, 1980 (in Russian).

8. Leonard, J. W. Tension Structures. Behaviour \& Analysis. McGraw-Hill, New York, 1988.

9. Kanno, Y. and Ohsaki, M. Large deflection analysis of cable networks by second-order cone program. In IASS Symposium 2001. Extended Abstracts. Nagoya, 2001, 124-125.

10. Agocs, Z. Cable structures and cable as a structural element. In IASS Symposium 2001. Extended Abstracts. Nagoya, 2001, 120-121. 
11. Õiger, K. Actions of panels and other roof elements on the work of saddle-shape suspended cable structures. Trans. Tallinn Polytechn. Inst., 1985, No. 596, 53-65 (in Russian).

12. Kulbach, V. and Õiger, K. Über die Ausgangsgeometrie vorgespannter Seilnetzwerke. Proc. Tallinn Polytechn. Inst., 1969, No. 278, 105-118 (in Russian).

13. Õiger, K. Actual Behaviour, Analysis and Design of Thin Saddle-shaped Shell Roofs. Thesis for the degree of Doctor of Technology, Tampere, 1992.

14. Kulbach, V. and Õiger, K. Investigation and erection of the saddle-shaped suspended cable-tent and wooden shell roofs. In Proc. 1st International Conference on Lightweight Structures in Architecture, Sydney, 1986, 580-587.

\title{
Lamedate puidust ja koorik-tross komposiitkonstruktsioonis katusekoorikute uurimine ja projekteerimine
}

\author{
Karl Õiger
}

On antud ülevaade Tallinna Tehnikaülikooli ehitiste projekteerimise instituudis viimastel aastakümnetel lamedate puidust ja komposiitkonstruktsioonis katusekoorikute alal teostatud uuringutest. Arvukalt on tehtud nimetatud konstruktsioonide mudelkatsetusi ning välja on töötatud nende arvutamise ja projekteerimise meetodeid. 